Document downloaded from:

http://hdl.handle.net/10251/54626

This paper must be cited as:

Guiñon Pina, V.; Dalmau, A.; Devesa, F.; Igual Muñoz, AN.; Amigó Borrás, V. (2015). Tribocorrosion behavior of beta titanium biomedical alloys in phosphate buffer saline solution. Journal of the Mechanical Behavior of Biomedical Materials. 46:59-68. doi:10.1016/j.jmbbm.2015.02.016.

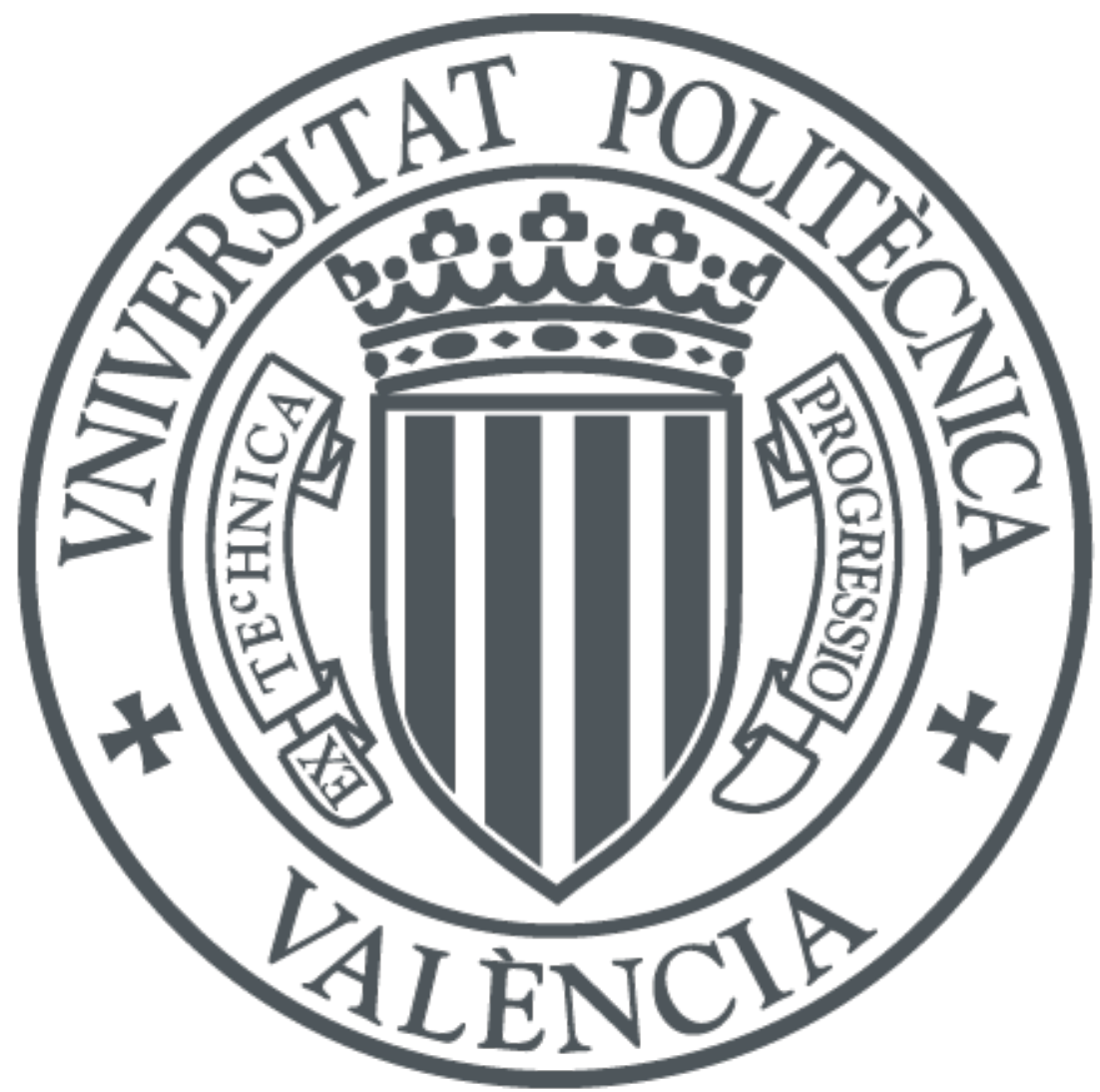

The final publication is available at

http://dx.doi.org/10.1016/j.jmbbm.2015.02.016

Copyright Elsevier

Additional Information 


\title{
Tribocorrosion behavior of beta titanium biomedical alloys in phosphate buffer saline solution
}

\author{
V. Guiñón Pina ${ }^{1)}$, A. Dalmau ${ }^{1)}$, F. Devesa ${ }^{2)}$, V. Amigóo ${ }^{2)}$ A. Igual Muñoz ${ }^{1)^{*}}$, \\ 1) Institute for Industrial, Radiophysical and Environmental Safety, Universitat Politècnica de València, \\ P.O. BOX 22012, E-46071, Valencia, Spain \\ ${ }^{2)}$ Institute of Materials Technology, Universitat Politècnica de València, P.O. BOX 22012, E-46071, \\ Valencia, Spain \\ *Corresponding author: virgupi@gmail.com
}

\begin{abstract}
The tribo-electrochemical behavior of different $\beta$ titanium alloys for biomedical applications sintered by powder metallurgy has been investigated. Different mechanical, electrochemical and optical techniques were used to study the influence of the chemical composition, Sn content, and the electrochemical conditions on the tribocorrosion behavior of those alloys Ti30NbxSn alloys (where " $\mathrm{x}$ " is the weight percentage of Sn content, $2 \%$ and $4 \%$ ).

Sn content increases the active and passive dissolution rate of the titanium alloys, thus increasing the mechanically activated corrosion under tribocorrosion conditions. It also increases the mechanical wear of the alloy. Prevailing electrochemical conditions between -1 and $2 \mathrm{~V}$ influences the wear accelerated corrosion by increasing it with the applied potential and slightly increases the mechanical wear of Ti30Nb4Sn.

Wear accelerated corrosion can be predicted by existing models as a function of electrochemical and mechanical parameters of the titanium alloys.
\end{abstract}

Keywords: tribocorrosion; titanium alloys; passivation; biomaterials 


\section{Introduction}

The use of titanium and its alloys in the biomedical field have considerably increased due to their excellent corrosion resistance and high biocompatibility $[1,2]$. Ti6Al4V alloy has been employed during years, although it was found to be toxic due to the release of aluminum and vanadium ions [3]. Recent efforts have focused on developing new titanium alloys, specifically $\beta$ titanium alloys containing $\mathrm{Nb}, \mathrm{Mo}, \mathrm{Zr}$ or Ta, which are considered non-toxic [4]. Furthermore, $\beta$ titanium alloys have a low young modulus (around $60 \mathrm{GPa}$ ), closer to the modulus of the cortical bone which lies around $20 \mathrm{GPa}$, this decreasing the risk of stress shielding that together with tribocorrosion are known to be responsible of the aseptic loosening of the implants $[5,6]$.

By conventional powder metallurgy elemental powders are mixed and good final properties of the alloy, such tensile stresses, specific strength and a good combination of toughness and fatigue resistance are obtained despite of the inherent porosity of the process [7]. It avoids the remelting of the material and subsequent heat treatments performed in the fusion process [8]. Nowadays porous titanium has become a popular surgical implant material since it increases the roughness and the porosity of the material, thus increasing the integration of the material device to the bone [9-11]. As the roughness increases the osseointegration is greater, but the active surface is also higher promoting the corrosion and the formation of oxides on the titanium surface [12]. An homogeneous microstructure is achieved even though all the diffusion process is conducted in solid state [13]. Sn favors to the titanium-niobium due to its relatively low melting point and form a liquid phase in the sintering phase [14]. However, it has been also shown that $\mathrm{Sn}$ dissolves preferentially in the Ti30Nb alloys, decreasing the corrosion resistance when adding above $2 \%$ in $\mathrm{Sn}$ [15]. With respect to the effect of Sn on the mechanical behavior of TiNbSn alloys, several studies have shown that microstructure and the mechanical properties of hot rolled $\mathrm{Ti}-35 \mathrm{Nb}-\mathrm{XSn}$ alloys $(x=2.5 ; 5.0 ; 7.5)$ depends on $\mathrm{Sn}$ addition into the $\mathrm{Ti}-35 \mathrm{Nb}$ alloys which helps stabilizing the $\beta$ phase and the mechanical behavior of those alloys up to 6.25 at $\%$ [S. Griza, D.H.G. de Souza Sá, W.W. Batista, J.C.G. de Blas, L.C. Pereira, Microstructure and mechanical properties of hot rolled TiNbSn alloys, Mater. Des. 56 (2014) 200-208 J.J. Gutiérrez-Moreno, Y. Guo, K. Georgarakis, A.R. Yavari, G.A. Evangelakis, C.E. Lekka, The role of Sn doping in the $\beta$-type Ti-25\%atNb alloys: Experiment and ab initio calculations, J. Alloys Compd. 615, Supplement 1 (2014) S676-S679]. Indeed, the hot rolled $\mathrm{Ti}-35 \mathrm{Nb}-2.5 \mathrm{Sn}$ alloy showed high ratio between strength and elastic modulus as well as high ductility.

The corrosion behavior of titanium alloys depends on the formation of an oxide film mainly composed of $\mathrm{TiO}_{2}$, which spontaneously covers the titanium surface and its alloys in presence of oxygen and/or water [3]. The chemical properties of the oxide layer play an important role in the biocompatibility of titanium implants and the surrounding tissues. Therefore the corrosion behavior of $\beta$ Ti alloys is governed by the role of the $\beta$ stabilizer elements on the passive film. For example, the presence of 
niobium in the alloy enhances the passivation characteristics of the film by decreasing the concentration of the anion vacancies in the $\mathrm{TiO}_{2}$ film [3]. Indeed, previous studies on TiNbSn alloys [15] in a phosphate buffered solution showed that the addition of $2 \%$ wt. of Sn increases the corrosion resistance and decreases the elastic modulus and the porosity of the alloy. Related to the citotoxicity of similar Ti-Nb-Sn alloys, there are many studies that confirmed they are suitable biomaterials due to their good cell adhesion or cell substrate interaction, thus they do not cause toxic effects [16-20].

Tribocorrosion is defined as the degradation of material surfaces that result from the combined action of mechanical loading and corrosion attack (chemical or electrochemical interaction) [21,22]. Implants are normally subjected to tribocorrosion $[23,24]$ because they have to support high loads under corrosive environments (i.e. saliva, synovial fluid). Electrochemical techniques are well suited for the investigation of the tribocorrosion phenomenon. Different studies on tribocorrosion mechanisms of titanium alloys [25-28] observed a synergistic effect between wear and corrosion that increase metal degradation rate. Otherwise, since titanium alloys are passive materials, chemical contribution to wear rate is less than $10 \%$ and they normally present an abrasive wear and plastic deformation [29-31]. Due to the poor wear resistance of Ti cp, new $\beta$ titanium alloys have been considered as biomedical alloys with good wear resistance. Yuyong et al [29] have studied the effect of mechanical properties on the wear behavior of TiNbSn alloys, but they did not study the synergism effect between wear and corrosion. Indeed, there are not studies about the effect of the alloying elements and the electrochemical conditions in those $\beta$ titanium alloys.

The aim of the present work is to study the influence of the chemical composition ( $\mathrm{Nb}$ and $\mathrm{Sn}$ content) and the mechanical properties of new $\beta$ titanium alloys on their triboelectrochemical behavior.

\section{Experimental}

\subsection{Materials and solution}

Three different $\beta$-titanium alloys have been studied: Ti30Nb, Ti30Nb2Sn and Ti30Nb4Sn, where the numbers indicate the weight percentage of the alloying elements $\mathrm{Nb}$ and $\mathrm{Sn}$ respectively. These alloys have been obtained by means of blending elemental powders and powder metallurgy process as mentioned elsewhere [14]. Samples were provided in form of disks of $25 \mathrm{~mm}$ in diameter and $3 \mathrm{~mm}$ thick. The specimens were not polished before testing, they were used as received, ultrasonically cleaned with acetone and ethanol for 5 minutes respectively in order to remove any existing particle from the pores, and air-dried. They have an average roughness of 2.45 $\mu \mathrm{m}$. After mounting the specimen and the counterpart on the tribometer, the solution was poured into the electrochemical cell. Only the upper surface of the samples $(2.56$

$\mathrm{cm}^{2}$ ) was exposed to the electrolyte and the lower part was insulated and electrically connected to the potentiostat. 
Tribocorrosion tests were conducted in a phosphate buffered solution (PBS) with the composition of $8 \mathrm{~g} / \mathrm{L} \mathrm{NaCl}, 0.2 \mathrm{~g} / \mathrm{L} \mathrm{KCl}, 1.44 \mathrm{~g} / \mathrm{L} \mathrm{Na} \mathrm{HPO}_{4}$ and $0.25 \mathrm{~g} / \mathrm{L} \mathrm{KH}_{2} \mathrm{KO}_{4}$. All chemicals were of analytical grade and doubly distilled water was employed in the preparation of the solutions. Temperature of the solution was kept at $37^{\circ} \mathrm{C}$.

\subsection{Mechanical characterization}

Microhardness and elastic modulus of the material have been obtained by nanoindentation test with a Nanoindenter G200 Agilent Technologies. A Berkovich diamond tip was used which area function was calibrated in a pattern of fuse silica. Test was performed with depth control up to $1500 \mathrm{~nm}$ and the stiffness of contact have been measured throughout the depth profile using the technique of continuous stiffness measure (CSM) from 600 to $1400 \mathrm{~nm}$.

\subsection{Electrochemical tests}

Electrochemical measurements were carried out using a potentiostat Solartron 1286 in order to characterize the cathodic kinetics on the titanium surface. A threeelectrode electrochemical setup included a platinum wire as counter electrode and a $\mathrm{Ag} / \mathrm{AgCl}(3 \mathrm{M} \mathrm{KCl})$ as reference electrode. All potentials were referred to the reference electrode (0.205 V versus standard hydrogen electrode, SHE).

Before any experiment, the samples were kept at a cathodic potential of -1.2 $\mathrm{V}_{\mathrm{Ag} / \mathrm{AgCl}}$ for $300 \mathrm{~s}$. Open circuit potential (OCP) was then measured for one hour. Cathodic potentiodynamic curves carried out from OCP to $-1.2 \mathrm{~V}_{\mathrm{Ag} / \mathrm{AgCl}}$ at a scan rate of $0.5 \mathrm{mV} / \mathrm{s}$.

Passivation kinetics was analyzed by potentiostatic tests. Current transients were measured at different applied potentials: $0 \mathrm{~V}_{\mathrm{Ag} / \mathrm{AgCl}}, 1 \mathrm{~V}_{\mathrm{Ag} / \mathrm{AgCl}}$ and $2 \mathrm{~V}_{\mathrm{Ag} / \mathrm{AgCl}}$ during $5 \mathrm{~min}$ at a high acquisition data rate $(1000 \mathrm{~Hz})$. The passivation charge $\mathrm{Q}_{\mathrm{p}}$ was then calculated by integrating the current density versus time.

\subsection{Tribocorrosion tests}

Tribocorrosion experiments were carried out on a ball-on-disk tribometer connected to the potentiostat. The counterpart was an alumina ball of $6 \mathrm{~mm}$ (SWIP AG Bruegg) in diameter with a maximum surface roughness of $0.02 \mu \mathrm{m} \mathrm{Ra}$ (according to manufacturer). These tests were performed at a sliding velocity at $60 \mathrm{rpm}$ sliding during 1 hour and applying a normal load of $5 \mathrm{~N}$ was applied on the counterpart (which corresponds to a maximum contact pressure of $960 \mathrm{MPa}$ ). The tribometer was connected to the potentiostat. Figure 1 shows a schema of the experimental set-up.

Two different tribocorrosion tests were carried out depending on the prevailing electrochemical conditions at open circuit potential or at a four different applied potentials, $-1 \mathrm{~V}_{\mathrm{Ag} / \mathrm{AgCl}}, 0 \mathrm{~V}_{\mathrm{Ag} / \mathrm{AgCl}}, 1 \mathrm{~V}_{\mathrm{Ag} / \mathrm{AgCl}}$ and $2 \mathrm{~V}_{\mathrm{Ag} / \mathrm{AgCl}}$. These potentials have been 
selected according to the cathodic and passive domains of the considered alloys and analyzed in previous paper [15]. This kind of test allows for fixing a well-define surface chemistry and to measure the electrochemical kinetics through the current measurement. The experimental sequence consisted of:

- Cathodic polarization by applying a potential of $-1.1 \mathrm{~V}_{\mathrm{Ag} / \mathrm{AgCl}}$ for $5 \mathrm{~min}$.

-Open circuit potential measurement or polarization at several applied potentials (-1 $\mathrm{V}_{\mathrm{Ag} / \mathrm{AgCl}}, 0 \mathrm{~V}_{\mathrm{Ag} / \mathrm{AgCl}}, 1 \mathrm{~V}_{\mathrm{Ag} / \mathrm{AgCl}}$ or $2 \mathrm{~V}_{\mathrm{Ag} / \mathrm{AgCl}}$ ) for $60 \mathrm{~min}$.

- Sliding for $60 \mathrm{~min}$ while the open circuit potential or the polarization is maintained.

- Sliding is stopped while the open circuit potential or polarization is maintained for 20 $\min$.

Wear was quantified using confocal microscopy (Olympus LEXT OLS3000) and it was used to characterize surface topography in and around the wear track. For this, five profiles were measured across the wear track of each sample. The wear track volume was determined by multiplying the area of the profiles situated at heights below 0 (reference level corresponded to the non-rubbed area) and multiplying it by the length of the wear track. Optical microscopy and scanning electron microscopy, SEM (JEOL6300) were used to analyze wear tracks on the metal's disks and on the alumina counterparts.

All tests were repeated twice to check for reproducibility.

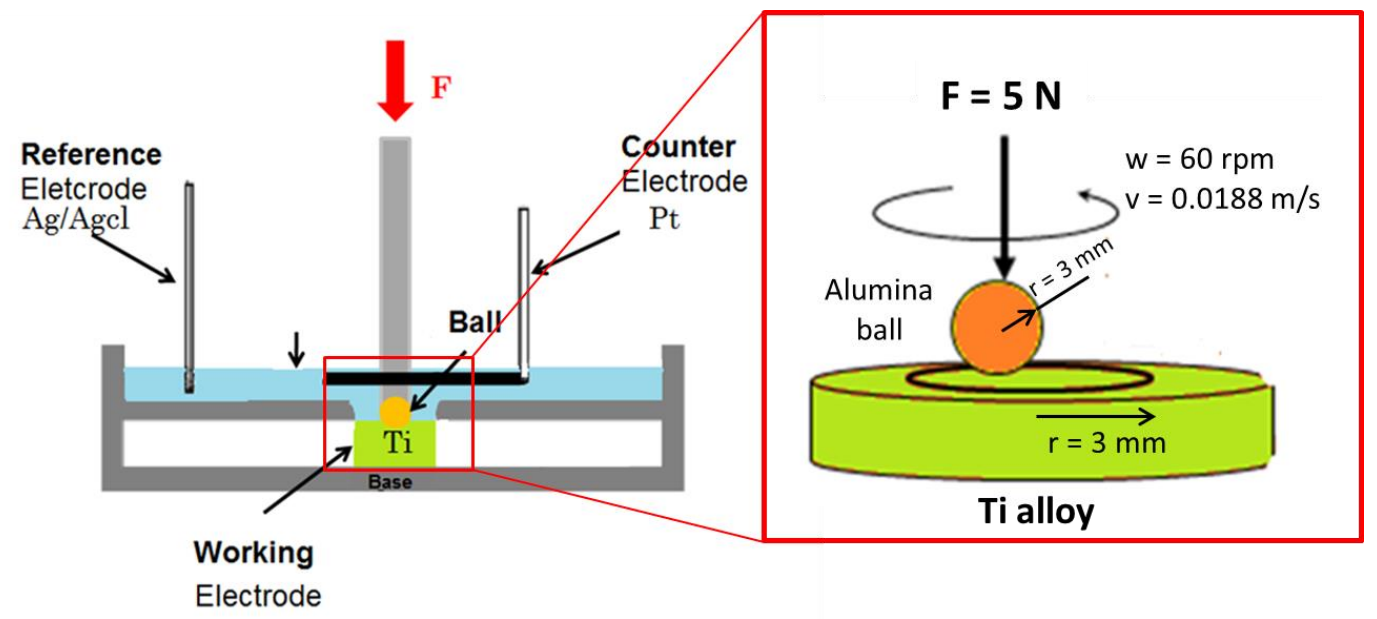

Figure 1. Schema of the experimental set-up of the tribometer with a horizontal electrochemical cell.

\section{Results}

\subsection{Mechanical characterization}

Table 1 shows the microhardness and the elastic modulus values of the titanium alloys. The addition of $\mathrm{Sn}$ to the Ti30Nb alloy does not modify its hardness but 
diminishes its elastic modulus due to the higher amount of $\beta$ phase generated by the diffusion of niobium into the Ti matrix.

Table 1. Mechanical characterization of Ti30Nb-xSn.

\begin{tabular}{lcc}
\hline Alloy & MicroHardness $\left(\mathbf{H V}_{\mathbf{0 . 2}}\right)$ & Elastic Modulus (GPa) \\
\hline Ti30Nb & $248 \pm 22$ & $93 \pm 3$ \\
Ti30Nb2Sn & $246 \pm 19$ & $89 \pm 3$ \\
Ti30Nb4Sn & $235 \pm 9$ & $86 \pm 5$ \\
\hline
\end{tabular}

\subsection{Electrochemical measurements}

Cathodic polarization curves of the Ti30Nb-xSn alloys are shown in Figure 2. In all cases electrochemical noise is observed around the corrosion potential. Below potentials of $-0.3 \mathrm{~V}_{\mathrm{Ag} / \mathrm{AgCl}}$ the current density linearly increases (in absolute value) with the applied potential with similar trend in all samples. Therefore, in this potential domain the cathodic Tafel equation (1) can be obtained through the linear regression of the current versus the applied potential of the cathodic polarization curves:

$$
\eta=a_{c}-b_{c} \log (i)
$$

where $\eta$ is the overpotential $\left(E-E_{c o r r}\right), a_{c}$ and $b_{c}$ the Tafel coefficients and $i$ the current density. By carrying out the linear regression, the Tafel coefficients were obtained and shown in Table 2.

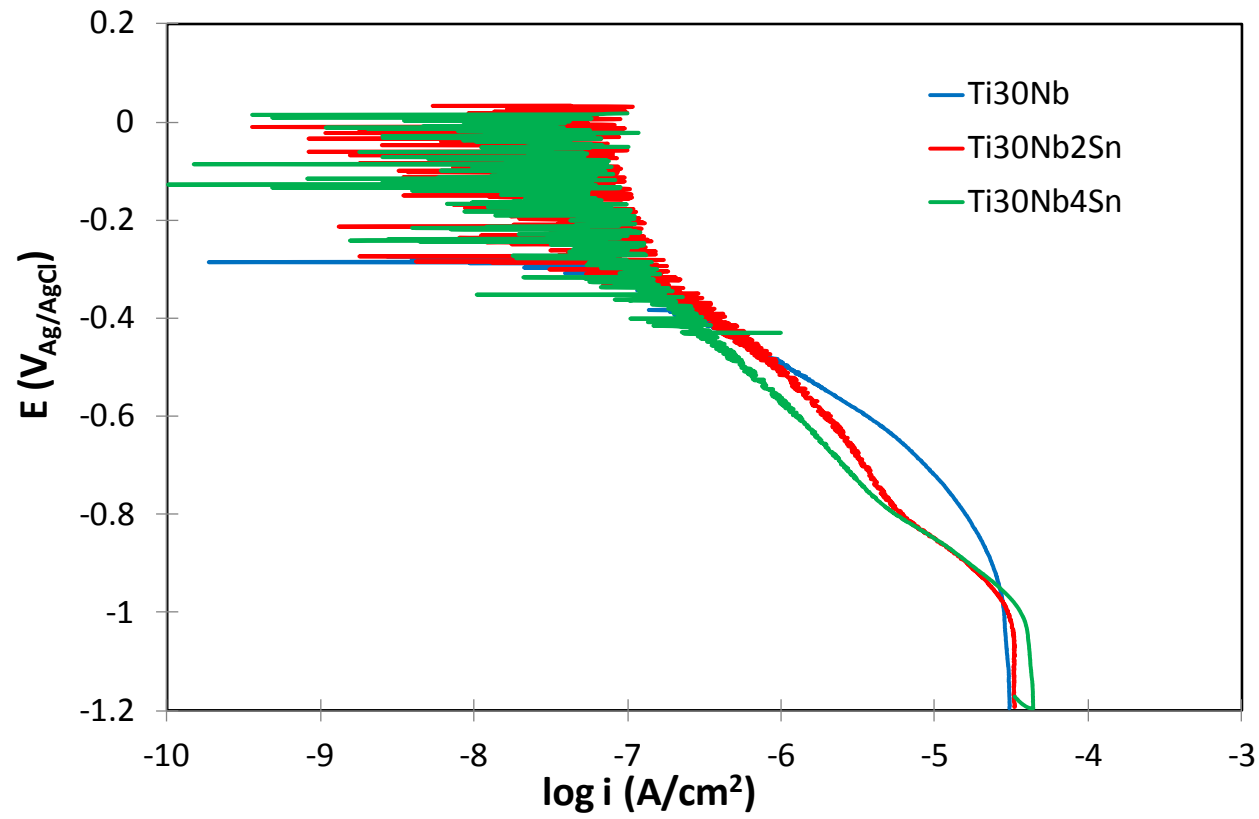

Figure 2. Cathodic polarization curves of Ti30Nb, Ti30Nb2Sn and Ti30Nb4Sn in PBS at $37^{\circ} \mathrm{C}$

Table 2. Tafel constants extracted from the linear regression of the cathodic polarization curves of Ti30NbxSn alloys. 


\begin{tabular}{lcc}
\hline Alloy & $\mathbf{a}_{\mathbf{c}}(\mathbf{m V})$ & $\mathbf{b}_{\mathbf{c}}(\mathbf{m V})$ \\
\hline Ti30Nb & -1.38 & 0.196 \\
Ti30Nb2Sn & -2.57 & 0.340 \\
Ti30Nb4Sn & -2.52 & 0.325 \\
\hline
\end{tabular}

In order to characterize the passivation kinetics of the titanium alloys, potentiostatic tests were carried out. Figure 3 shows an example of the typical current transients during passivation of the studied alloys at $0 \mathrm{~V}_{\mathrm{Ag} / \mathrm{AgCl}}$ in a double logarithmic scale. At the applied potential, the current is constant during the first $50 \mathrm{~ms}$ due to passive film formation, and then it sharply decreases due to film thickening.

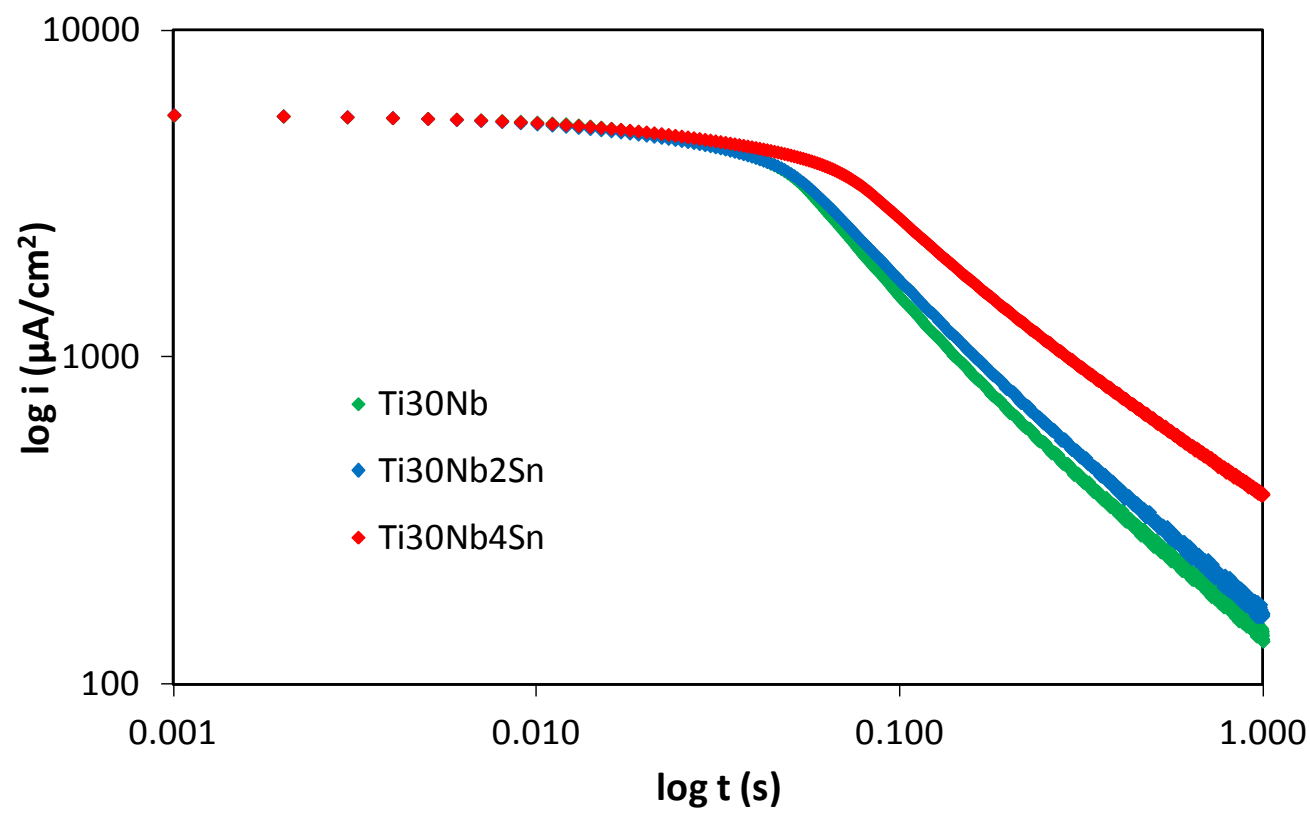

Figure 3. Passivation transients at $0 \mathrm{~V}_{\mathrm{Ag} / \mathrm{AgCl}}$ of the studied alloys in $\mathrm{PBS}$ at $37^{\circ} \mathrm{C}$.

Table 3 shows the $Q_{p}$ values of the Ti30NbxSn samples at different passive potentials. The charge $(\mathrm{Q})$ is proportional to the oxidized cations and it increases with the applied potential and with the Sn content. This trend is in good agreement with the previously reported passivation behavior of Ti30NbxSn alloys [15].

Table 3. Passivation charge densities $\left(\mathrm{Q}_{\mathrm{p}}\left(\mathrm{mC} / \mathrm{cm}^{2}\right)\right)$ of the studied alloys in PBS at $37^{\circ} \mathrm{C}$.

\begin{tabular}{lccc}
\hline \multicolumn{1}{c}{ Alloy } & $\mathbf{0} \mathbf{V}_{\mathbf{A g} / \mathbf{A g C l}}$ & $\mathbf{1} \mathbf{V}_{\mathbf{A g} / \mathbf{A g C l}}$ & $\mathbf{2} \mathbf{V}_{\mathrm{Ag} / \mathrm{AgCl}}$ \\
\hline Ti30Nb & 2.08 & 3.89 & 6.42 \\
Ti30Nb2Sn & 2.55 & 5.24 & 8.60 \\
Ti30Nb4Sn & 5.33 & 12.89 & 21.37 \\
\hline
\end{tabular}

\subsection{Tribocorrosion tests at $\mathrm{OCP}$}


The evolution of the open circuit potential with time of the titanium alloys is monitored before, during and after the sliding and it is shown in Figure 4.

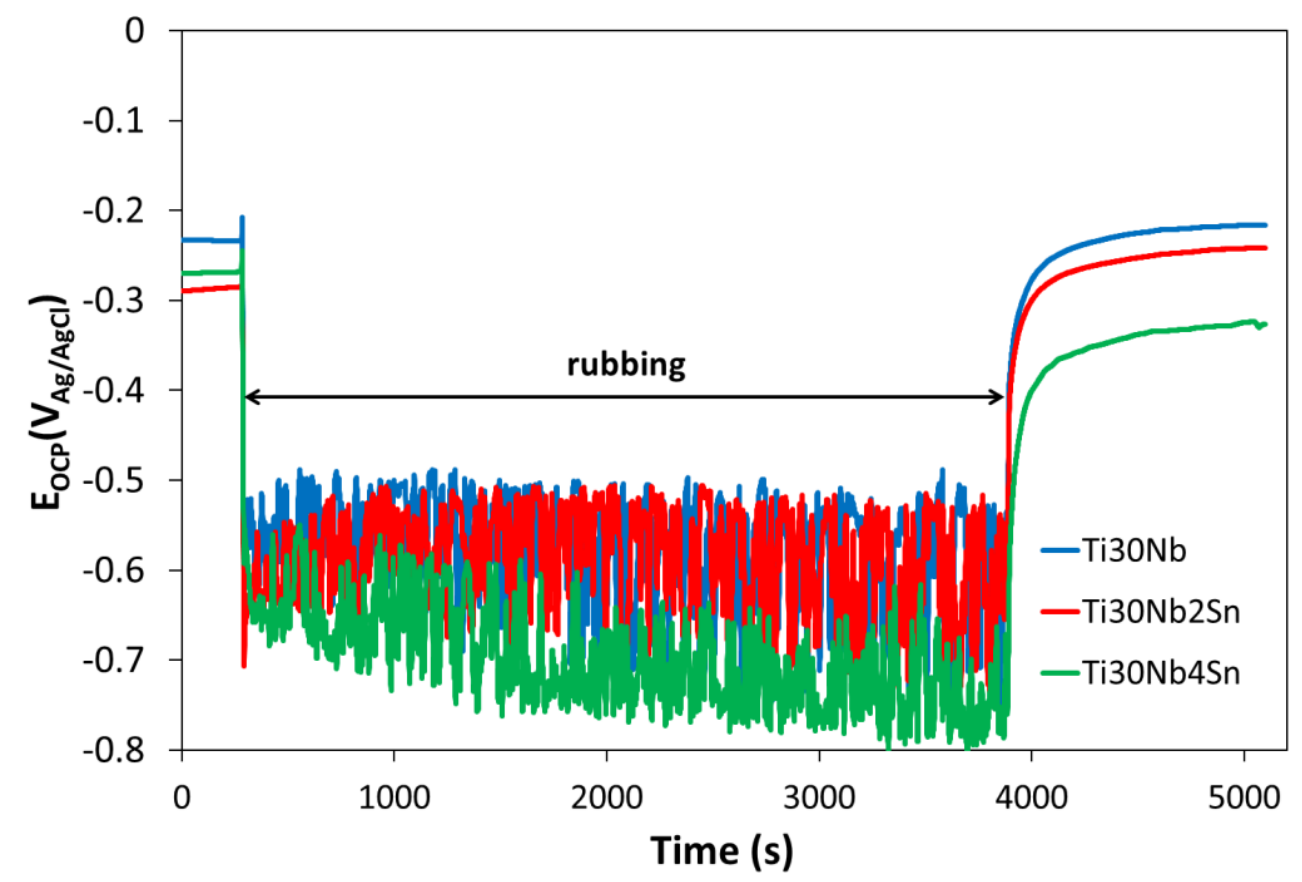

Figure 4. OCP evolution with time during sliding of a smooth alumina ball against Ti30Nb (a), Ti30Nb2Sn (b) and Ti30nb4Sn (c) in PBS at $37^{\circ} \mathrm{C}$.

Before the sliding the measured open circuit potential reflects the presence of a passive film on the alloy. An abrupt decrease in potential is observed immediately after initiation of the sliding, indicating a depassivation of the surface induced by the mechanical detachment of the passive film and the exposure of fresh active titanium to the electrolyte [1,32]. The OCP during rubbing results from the galvanic coupling between the depassivated wear track (anode) and the passive unworn area (cathode) [3335].

During the sliding the OCP remains practically constant indicating that a depassivated state prevails in the wear track. The potential shows variations of about $0.1 \mathrm{~V}$ due to the establishment of a dynamic equilibrium between depassivation and repassivation mechanisms as a result from the periodic removal and growth of the passive film in the sliding. At the end of the sliding, the open circuit potential exhibits an anodic shift, suggesting the occurrence of repassivation of the active area of the worn zone.

There is a small trend of decreased $\mathrm{OCP}_{\text {sliding }}$ with the increase in Sn content in the alloy.

\subsection{Tribocorrosion tests at applied potentials}


The current evolution with time during sliding an alumina ball against the studied titanium alloys at $-1 \mathrm{~V}_{\mathrm{Ag} / \mathrm{AgCl}}$ is shown in Figure 5(a) and the current evolution for Ti30Nb alloy at $0 \mathrm{~V}_{\mathrm{Ag} / \mathrm{AgCl}}, 1 \mathrm{~V}_{\mathrm{Ag} / \mathrm{AgCl}}$ and $2 \mathrm{~V}_{\mathrm{Ag} / \mathrm{AgCl}}$ in Figure 5(b), corresponding to the cathodic and the anodic (passive) domains of the alloys respectively.

At $-1 \mathrm{~V}_{\mathrm{Ag} / \mathrm{AgCl}}$ the current in all samples is negative, corresponding to the measurement of the cathodic reaction rate. Slightly higher current (in absolute value) was obtained in the Ti30Nb4Sn. At the onset of rubbing current increases (in absolute value) due to the stirring effect of the counterpart, which enhances mass transport and the mechanical removal of the passive film, which is known to inhibit the cathodic reaction. Slightly higher current was measured in the Ti30Nb4Sn.

At the applied anodic potentials, the whole titanium surfaces are initially passive and the anodic current $\left(\mathrm{I}_{0}\right)$ is low (below $4 \mu \mathrm{A}$ ). When sliding starts, current exhibited a sharp increase due to the mechanical detachment of the passive film [32] and the steady state value was reached after few seconds. After the initial increase in current, no significant variation in the current is observed during the tribocorrosion tests. When the sliding is stopped, the current sharply decreased again to the value observed at the beginning of the tests, which suggests the occurrence of repassivation of the worn area. The same behavior in different passive system was observed by different authors $[33,36,37]$. 

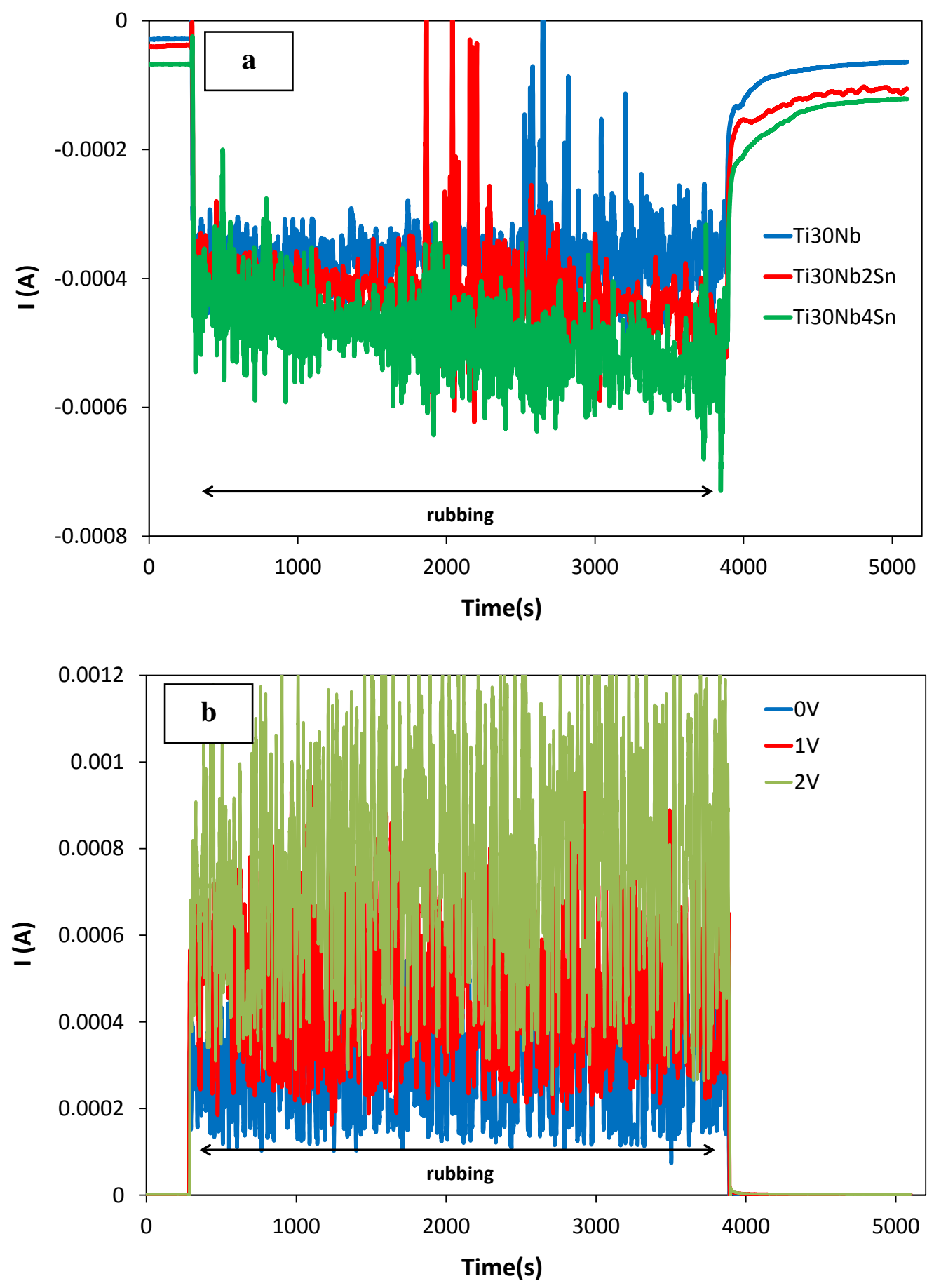

Figure 5. Current evolution with time during sliding of a smooth alumina ball (a) against Ti30Nb, Ti30Nb2Sn and Ti30Nb4Sn at $-1 \mathrm{~V}_{\mathrm{Ag} / \mathrm{AgCl}}$ and (b) against Ti30Nb at $0 \mathrm{~V}_{\mathrm{Ag} / \mathrm{AgCl}}, 1$ $\mathrm{V}_{\mathrm{Ag} / \mathrm{AgCl}}$ and $2 \mathrm{~V}_{\mathrm{Ag} / \mathrm{AgCl}}$ in $\mathrm{PBS}$ at $37^{\circ} \mathrm{C}$.

Table 4 summarizes the average values of the current before and during the sliding in the tribocorrosion tests carried out at the different applied potentials. The current flowing from the wear track $\left(\mathrm{I}_{\text {sliding }}\right)$ was determined by subtracting from the current measured during sliding the value of the current measured before starting the sliding. The latter was assumed to correspond approximately to the current flowing through the area outside the wear track during sliding (the wear track area is much 
smaller than the total electrode area). There is an increase in current before and during sliding with the applied potential and the increase in Sn content in the alloy. However, the influence of the applied potential and the chemical composition of the alloy on the current are less significant during the sliding. Passive current measured in Ti30Nb4Sn are 10 times higher than the values obtained in Ti30Nb, while they are less than 2 times higher under sliding conditions.

Table 4. Average values of the current measured before $\left(\mathrm{I}_{0}\right)$ and during sliding $\left(\mathrm{I}_{\text {sliding }}\right)$ of the titanium alloys sliding against an alumina ball. Normal force $5 \mathrm{~N}$.

\begin{tabular}{|c|c|c|c|c|c|c|c|c|}
\hline & \multicolumn{2}{|c|}{$-1 \mathrm{~V}_{\mathrm{Ag} / \mathrm{AgCl}}$} & \multicolumn{2}{|c|}{$\mathbf{0} \mathbf{V}_{\mathrm{Ag} / \mathrm{AgCl}}$} & \multicolumn{2}{|c|}{$1 \mathrm{~V}_{\mathrm{Ag} / \mathrm{AgCl}}$} & \multicolumn{2}{|c|}{$2 \mathrm{~V}_{\mathrm{Ag} / \mathrm{AgCl}}$} \\
\hline & $\begin{array}{c}\mathbf{I}_{0} \\
(\boldsymbol{\mu} \mathbf{A})\end{array}$ & $\begin{array}{c}\mathbf{I}_{\text {Sliding }} \\
(\boldsymbol{\mu A})\end{array}$ & $\begin{array}{c}\mathbf{I}_{0} \\
(\boldsymbol{\mu A})\end{array}$ & $\begin{array}{c}\mathbf{I}_{\text {Sliding }} \\
(\boldsymbol{\mu A})\end{array}$ & $\begin{array}{c}\mathbf{I}_{0} \\
(\mu \mathbf{A})\end{array}$ & $\begin{array}{r}\mathbf{I}_{\text {sliding }} \\
(\boldsymbol{\mu} \mathbf{A})\end{array}$ & $\begin{array}{c}\mathbf{I}_{0} \\
(\boldsymbol{\mu A})\end{array}$ & $\begin{array}{c}\mathbf{I}_{\text {sliding }} \\
(\boldsymbol{\mu} \mathbf{A})\end{array}$ \\
\hline Ti30Nb & $-40 \pm 16$ & $-326 \pm 15$ & $0.58 \pm 0.71$ & $275 \pm 27.6$ & $1.77 \pm 1.8$ & $451 \pm 32.6$ & $1.91 \pm 0.45$ & $723 \pm 18.3$ \\
\hline Ti30Nb2Sn & $-45 \pm 9$ & $-336 \pm 65$ & $1.04 \pm 1.44$ & $292 \pm 68.2$ & $5.40 \pm 2.9$ & $490 \pm 12.6$ & $6.50 \pm 1.30$ & $804 \pm 38.5$ \\
\hline Ti30Nb4Sn & $-62 \pm 6$ & $-311 \pm 156$ & $1.70 \pm 2.20$ & $342 \pm 96.2$ & $16.30 \pm 16.9$ & $543 \pm 13.9$ & $23.9 \pm 5.02$ & $1056 \pm 43.1$ \\
\hline
\end{tabular}

At all considered potentials, the increase of the anodic current is higher in Ti30Nb4Sn, indicating that this alloy undergoes higher anodic dissolution.

\subsection{Friction and wear quantification}

Friction coefficients were registered simultaneously to the electrochemical signal and remained constant around a fix value during the whole tests. The average values of the friction coefficients of all the studied alloys and at all potentials during sliding are listed in Table 5. An increase in $\mu$ with the Sn content is observed in all situations.

Table 5. Average values of friction coefficient $(\mu)$ of the titanium alloys sliding against an alumina ball.

\begin{tabular}{cccccc}
\hline $\boldsymbol{\mu}$ & $\mathbf{- 1} \mathbf{V}_{\mathbf{A g} / \mathbf{A g C l}}$ & $\mathbf{O C P}$ & $\mathbf{0} \mathbf{V}_{\mathbf{A g} / \mathbf{A g C l}}$ & $\mathbf{1} \mathbf{V}_{\mathbf{A g} / \mathbf{A g C l}}$ & $\mathbf{2} \mathbf{V}_{\mathbf{A g} / \mathbf{A g C l}}$ \\
\hline Ti30Nb & $0.64 \pm 0.039$ & $0.59 \pm 0.01$ & $0.60 \pm 0.01$ & $0.59 \pm 0.02$ & $0.60 \pm 0.02$ \\
Ti30Nb2Sn & $0.66 \pm 0.004$ & $0.61 \pm 0.04$ & $0.60 \pm 0.06$ & $0.62 \pm 0.02$ & $0.58 \pm 0.01$ \\
Ti30Nb4Sn & $0.72 \pm 0.005$ & $0.71 \pm 0.01$ & $0.68 \pm 0.07$ & $0.67 \pm 0.02$ & $0.70 \pm 0.01$ \\
\hline
\end{tabular}

Table 6 shows the microhardness values inside the wear track of the titanium alloys after the tribocorrosion tests under different electrochemical conditions. In general there is an increase in microhardness due to the work hardening caused by the sliding, and no clear influence of the potential on microhardness is observed. 
Table 6. Microhardness of the titanium alloys after the tribocorrosion test in the wear track at the different applied potentials in $\mathrm{PBS}$ at $37^{\circ} \mathrm{C}$.

\begin{tabular}{lccccc}
\hline \multicolumn{1}{c}{ HV } & $\mathbf{- 1 V}$ & OCP & OV & 1V & 2V \\
\hline Ti30Nb & $331 \pm 17$ & $362 \pm 63$ & $330 \pm 31$ & $337 \pm 60$ & $272 \pm 21$ \\
Ti30Nb2Sn & $279 \pm 15$ & $322 \pm 24$ & $329 \pm 18$ & $310 \pm 12$ & $266 \pm 27$ \\
Ti30Nb4Sn & $273 \pm 37$ & $333 \pm 26$ & $276 \pm 23$ & $333 \pm 15$ & $267 \pm 28$ \\
\hline
\end{tabular}

In a tribocorrosion system several mechanisms simultaneously take place generating material loss: wear accelerated corrosion $\left(\mathrm{V}_{\text {wac }}\right)$ and mechanical removal of particles $\left(\mathrm{V}_{\text {mech }}\right)$ in the wear track and corrosion $\left(\mathrm{V}_{\text {corr }}\right)$ outside the wear track. Therefore the overall material loss can be expressed according to the following relationship:

$$
\mathrm{V}_{\text {tot }}=\mathrm{V}_{\text {wac }}+\mathrm{V}_{\text {mech }}+\mathrm{V}_{\text {corr }}
$$

Since $\mathrm{V}_{\text {corr }}$ can be considered negligible for the titanium alloys (passive alloys), the overall material loss is simplified by the sum of the mechanical and wear accelerated corrosion volumes, $\mathrm{V}_{\text {tot }}=\mathrm{V}_{\mathrm{wac}}+\mathrm{V}_{\text {mech }}$.

The material loss removed by anodic oxidation in the wear track, $\mathrm{V}_{\text {wac }}$ was calculated from the measured current using Faraday's law:

$$
\mathrm{V}_{\mathrm{wac}}=\frac{\mathrm{I}_{\text {sliding }} \cdot \mathrm{t} \cdot \mathrm{M}}{\mathrm{n} \cdot \mathrm{F} \cdot \rho}
$$

where $\mathrm{M}$ is the atomic mass of Ti30Nb, Ti30Nb2Sn and Ti30Nb4Sn $(61.4,62.8$ and $64.2 \mathrm{~g} / \mathrm{mol}$ respectively), $\mathrm{n}$ is the charge number for the oxidation reaction (valence of oxidation was assumed 4$), \mathrm{F}$ is the Faraday constant $(96,500 \mathrm{C} / \mathrm{mol}), \rho$ is the density of the alloys equal to $4,25 \mathrm{~g} / \mathrm{cm}^{3}$ and $\mathrm{t}$ is the duration of sliding, $3600 \mathrm{~s}$. The total wear volume, $\mathrm{V}_{\text {tot }}$ was determined geometrically by confocal microscopy. The area of an average cross section of the wear track multiplied by the length of the track gives one the $\mathrm{V}_{\text {tot }}$.

Wear accelerated corrosion volume at $\mathrm{OCP}$ has been determined according to the model proposed by Vieria et al [38] and applied by Papageorgiou and Mischler [26], which takes into account the cathodic kinetics and the corrosion potential of the alloys, the potential during sliding and the anode to cathode ratio. From this model, the anodic current passing through the wear track $\left(i_{a}\right)$ was calculated by using the following equation:

$$
\log i_{a}=\frac{E_{c o r r}-E_{c}+a_{c}}{b_{c}}-\log \left(\frac{A_{a}}{A_{c}}\right)
$$

Where $\mathrm{E}_{\mathrm{c}}$ is the potential measured during rubbing $\left(\mathrm{OCP}_{\text {sliding }}\right), \mathrm{E}_{\text {corr }}$ is the corrosion potential, $a_{c}$ and $b_{c}$ are the Tafel constants extracted from the cathodic polarization curves by linear regression of the curve in Figure 2. $A_{a}$ corresponds to the 
wear track area obtained by the confocal profile at the end of the experiment, $A_{c}$ corresponds to the cathode area which can be approximated by the sample area $\left(2.56 \mathrm{~cm}^{2}\right)$.

The obtained $\mathrm{V}_{\text {wac }}$ values are listed in Table 7 together with the mechanical wear volume $\left(\mathrm{V}_{\text {mech }}\right)$ and total wear volume $\left(\mathrm{V}_{\text {tot }}\right)$. $\mathrm{V}_{\text {mech }}$ removed by tribocorrosion is obtained by the difference between $\mathrm{V}_{\text {tot }}$ and $\mathrm{V}_{\text {wac }}$. Two independent measurements are shown under each condition.

Table 7. Wear volumes $x 10^{-3}\left(\mathrm{~mm}^{3}\right)$ of the titanium alloys in $\mathrm{PBS}$ at $37^{\circ} \mathrm{C}$.

\begin{tabular}{|c|ccc|ccc|ccc|}
\hline \multirow{2}{*}{$\mathbf{E}\left(\mathbf{V}_{\text {Ag/AgCl }}\right)$} & \multicolumn{3}{|c|}{ Ti30Nb } & \multicolumn{3}{c|}{ Ti30Nb2Sn } & \multicolumn{3}{c|}{ Ti30Nb4Sn } \\
\cline { 2 - 10 } & $\mathbf{V}_{\text {wac }}$ & $\mathbf{V}_{\text {mech }}$ & $\mathbf{V}_{\text {tot }}$ & $\mathbf{V}_{\text {wac }}$ & $\mathbf{V}_{\text {mech }}$ & $\mathbf{V}_{\text {tot }}$ & $\mathbf{V}_{\text {wac }}$ & $\mathbf{V}_{\text {mech }}$ & $\mathbf{V}_{\text {tot }}$ \\
\hline \multirow{2}{*}{-1} & & & 840 & & & 1578 & & & 1334 \\
& & & 872 & & & 1080 & & & 1020 \\
\hline \multirow{2}{*}{ OCP } & 0.03 & 805 & 806 & 0.03 & 977 & 1004 & 0.03 & 1051 & 1052 \\
& 0.02 & 815 & 826 & 0.03 & 1333 & 1358 & 0.02 & 1103 & 1103 \\
\hline \multirow{2}{*}{0} & 33 & 1111 & 1144 & 32 & 931 & 962 & 63 & 1670 & 1741 \\
& 38 & 1023 & 1061 & 41 & 1329 & 1370 & 56 & 1520 & 1575 \\
\hline \multirow{2}{*}{1} & 55 & 765 & 820 & 63 & 845 & 908 & 72 & 1354 & 1426 \\
& 61 & 1017 & 1078 & 66 & 1094 & 1160 & 75 & 1315 & 1390 \\
\hline \multirow{2}{*}{2} & 95 & 885 & 980 & 111 & 1369 & 1480 & 148 & 1682 & 1830 \\
& 89 & 1009 & 1098 & 99 & 1270 & 1369 & 139 & 1650 & 1789 \\
\hline
\end{tabular}

Wear accelerated corrosion at the applied passive potentials represents around $5 \%$ of the total wear, while at OCP, this contribution is negligible, being less than $0.5 \%$. A small increase of the wear volume when a $4 \%$ of $\mathrm{Sn}$ is added to the alloy at the applied passive potentials is observed. In general, there is not a clear influence of the electrochemical conditions on the wear volumes of the Ti alloys.

\subsection{Wear morphology}

Figure 6 shows SEM micrographs of the wear tracks of Ti30Nb2Sn at cathodic and anodic potentials, $-1 \mathrm{~V}_{\mathrm{Ag} / \mathrm{AgCl}}$ and $0 \mathrm{~V}_{\mathrm{Ag} / \mathrm{AgCl}}$, respectively. Ductile behavior and plastic deformation is observed. It appears loose particles or debris of work piece ranging from 0.5 to $6 \mu \mathrm{m}$, which is due to the action of the electrolyte and the applied potential. Scratches and grooves are also observed. There are not great differences in wear morphology neither with the Sn content nor with the applied potential.

Figure 7 shows an example of an optical image on the alumina ball at the end of the tribocorrosion test at $0 \mathrm{~V}_{\mathrm{Ag} / \mathrm{AgCl}}$ of the Ti30Nb4Sn. Many platelets of transferred titanium and loss of material on the alumina surface are observed. Similar patterns were observed under all the studied conditions. 

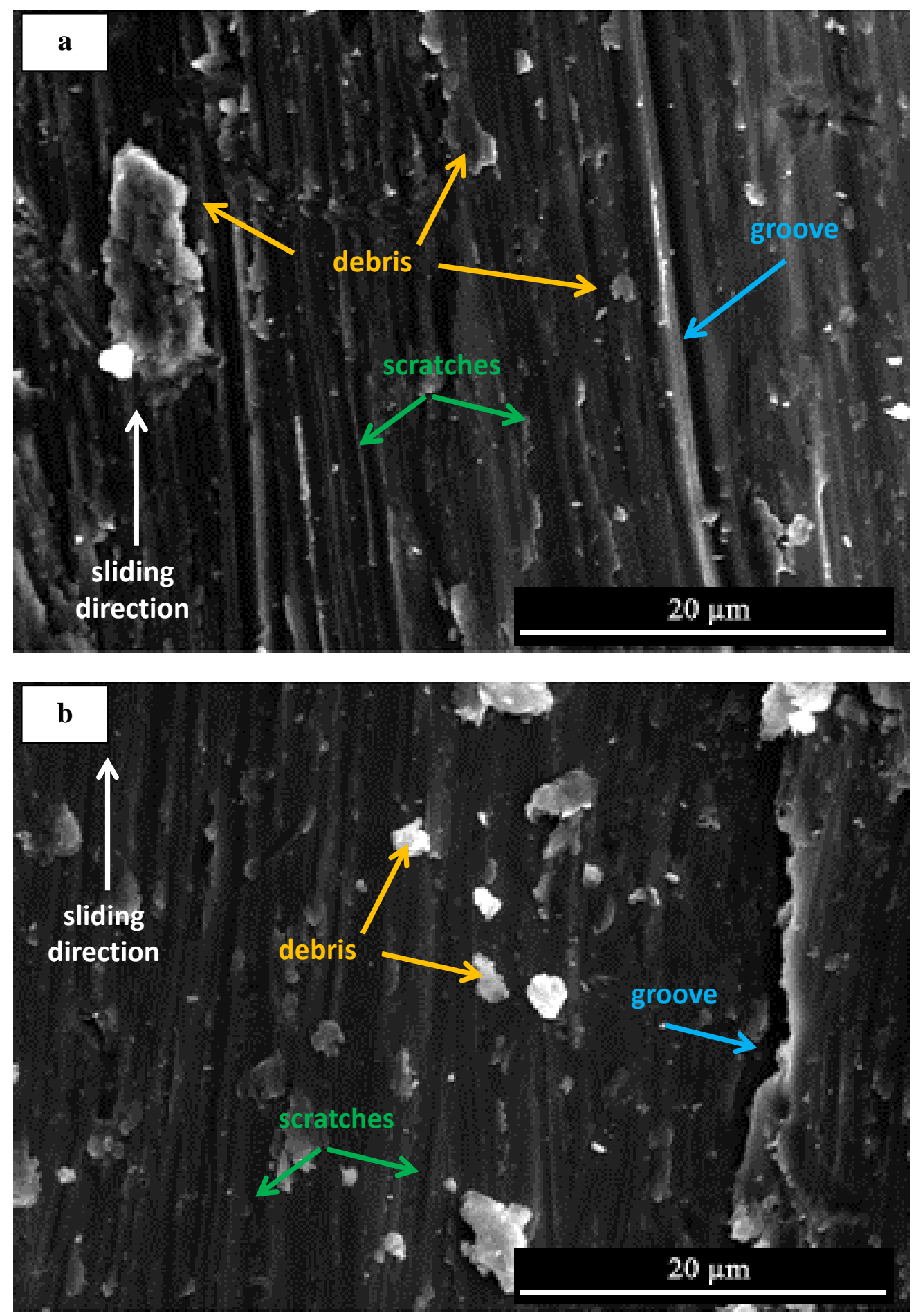

Figure 6. SEM images of the wear track of Ti30Nb2Sn at (a) $-1 \mathrm{~V}_{\mathrm{Ag} / \mathrm{AgCl}}$ and (b) $0 \mathrm{~V}_{\mathrm{Ag} / \mathrm{AgCl}}$. 


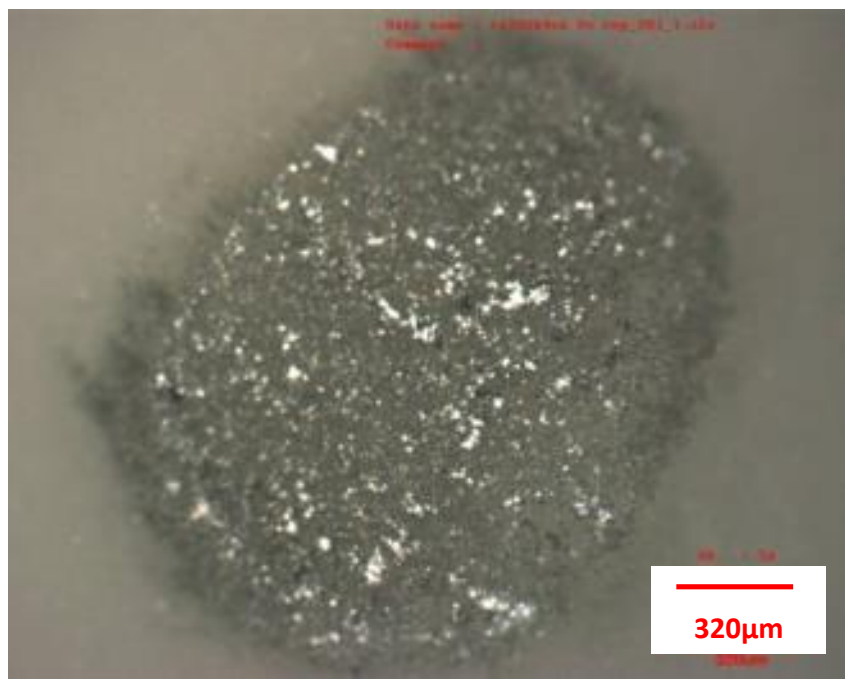

Figure 7. Optical Image of the alumina ball at the end of the tribocorrosion test at $0 \mathrm{~V}_{\mathrm{Ag} / \mathrm{AgCl}}$ of $\mathrm{Ti} 30 \mathrm{Nb} 4 \mathrm{Sn}$.

Significant amount of wear debris were observed outside the wear track under all electrochemical conditions. The number of particles increases with the applied potential and they have the same average size as inside the wear track. This behavior has been already observed by Jemmely et al. [23], where they studied the effect of applied potential, load and frequency on the tribocorrosion behavior of a ferritic stainless steel. They observed outside the wear track significant amounts of wear debris are observed at high potential, while at low potential wear debris are largely absent.

\section{Discussion}

\subsection{Influence of $\mathrm{Sn}$ content on the tribocorrosion behavior of Ti30NbxSn} alloys

Titanium alloys, Ti30NbxSn are known to passivate in PBS solutions [15]. The passivation charge density of the studied alloys, Table 3 , quantifies the amount of oxidized species at the selected potentials. This includes ions incorporated into the passive film in form of oxides and dissolved ions, which go into the solution [39]. By considering the ratios between $\mathrm{Q}_{\mathrm{p}}$ of the Ti30NbxSn with respect to the $\mathrm{Ti} 30 \mathrm{Nb}$ it is possible to obtain the acceleration of passive dissolution caused by the $\mathrm{Sn}$. Accordingly, passive dissolution of Ti30 $\mathrm{Nb} 4 \mathrm{Sn}$ and Ti30Nb2Sn is around 3 and 1.3 times higher than Ti30Nb respectively, at all studied potentials. Sn content in the alloy determines the passive dissolution rate of the titanium alloy, increasing the amount of oxidized cations approximately in a proportional way to the increase in Sn content.

Analyzing the effect of the Sn content on the wear accelerated corrosion under applied passive potential the ratio between $\mathrm{V}_{\text {wac }}$ of Ti30NbxSn with respect to the Ti30Nb can be calculated. At all applied potentials it lays between 1.5 and 1.1 for the 
Ti30Nb4Sn and Ti30Nb2Sn respectively. These values are lower than those observed in the corrosion potentiostatic tests, which indicates that Sn content has smaller influence on the mechanically activated corrosion of titanium alloys than on pure corrosion conditions. This is not surprising since the corrosion mechanism changes from passive dissolution (corrosion only) to active dissolution (tribocorrosion). Therefore, Sn content, mainly increases the passive dissolution rate of the titanium alloys.

On the other hand, and comparing the $\mathrm{V}_{\text {mech }}$ of the different alloys, there is no influence of the $\mathrm{Sn}$ addition below $2 \%$ and up to $1 \mathrm{~V}_{\mathrm{Ag} / \mathrm{AgCl}}$, while alloying the $\mathrm{Ti} 30 \mathrm{Nb}$ with $4 \% \mathrm{Sn}$, increases the mechanical volume loss 1.5 to 2 times depending on the applied potential.

Figure 8 shows the $\mathrm{V}_{\text {mech }}$ and $\mathrm{V}_{\text {wac }}$ of the studied alloys as a function of the Ti content in the alloy at the different applied potentials. In all cases there is a decreasing trend of the loss volumes with the Ti content. The highest Ti influence was found in the mechanically induced corrosion, Figure $8 \mathrm{~b}$, when the applied potential was $2 \mathrm{~V}_{\mathrm{Ag} / \mathrm{AgCl}}$, which is in good agreement with previous results where extremely high Sn dissolution was fund at $2 \mathrm{~V}_{\mathrm{Ag} / \mathrm{AgCl}}$ [15]. The $\mathrm{V}_{\text {mech }}$ does not depend on the selected potentials because in all case the alloy is passive. 

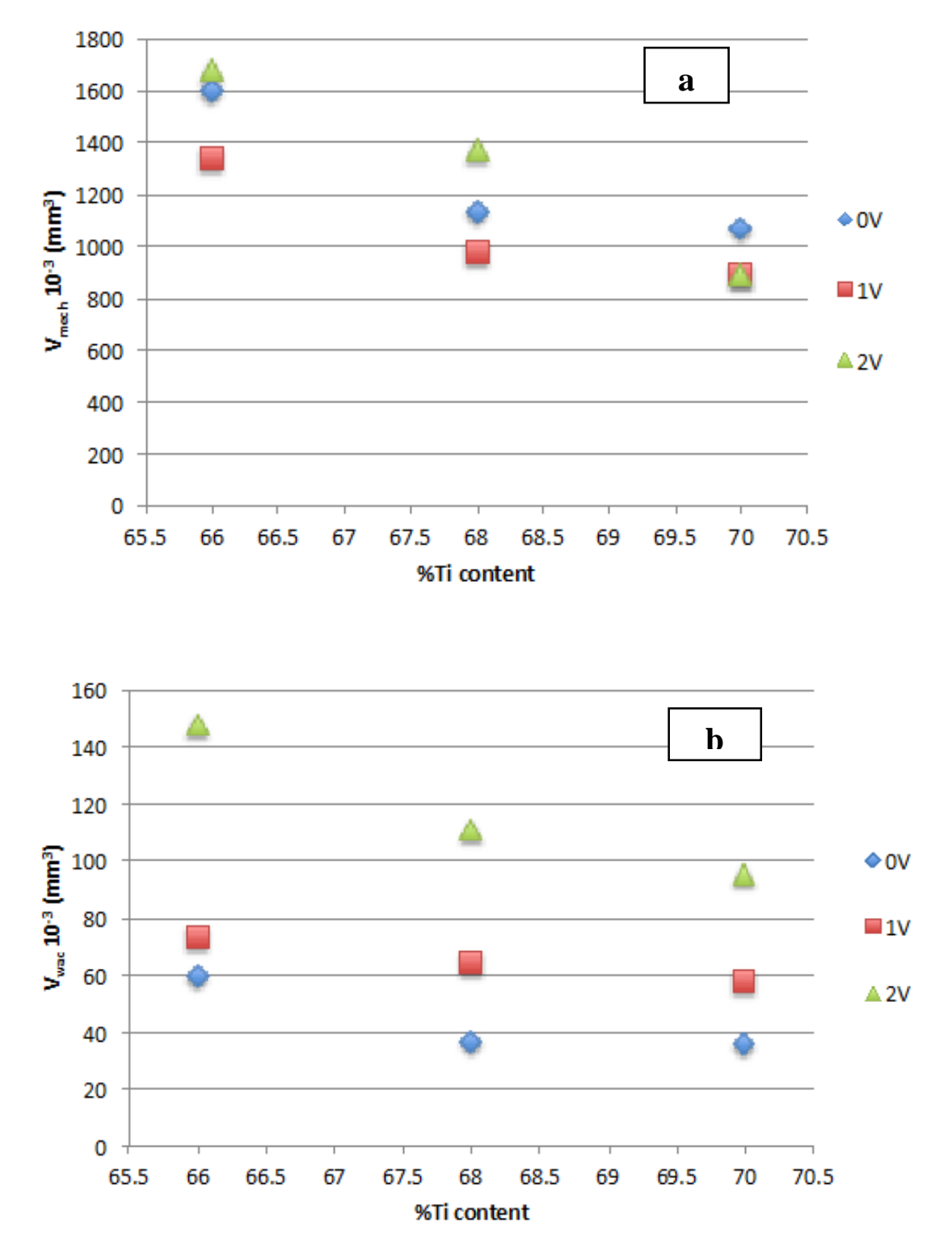

Figure 8. (a) $\mathrm{V}_{\text {mech }}$ and (b) $\mathrm{V}_{\text {wac }}$ as a function of the Ti content in the alloy at the different applied potentials in PBS at $37^{\circ} \mathrm{C}$.

The small differences in Hardness (reduction of $1 \%$ and $5 \%$ in the Ti30Nb2Sn and Ti30Nb4Sn with respect to the Ti30Nb respectively) cannot explain the influence of the $\mathrm{Sn}$ on the $\mathrm{V}_{\text {mech. }}$. Decrease in hardness and in $\mathrm{V}_{\text {mech }}$ of the Ti30NbxSn (in percentage) have been calculated with respect to the Ti30Nb values and shown in Table 8. $\mathrm{V}_{\text {mech }}$ increases more than $5 \%$ (for the Ti30Nb2Sn at $0 \mathrm{~V}$ ) and up to $47 \%$ (for the Ti30Nb4Sn at 2V) in the Sn-containing alloys depending on the applied potential and Sn content. Therefore one should think in a tribo-electrochemical mechanism involved in this system, which controls the degradation rate. 
Table 8. Average value of hardness decrease and $\mathrm{V}_{\text {mech }}$ increase (in $\%$ with respect to the $\mathrm{Ti} 30 \mathrm{Nb}$ values) of the Ti30NbxSn alloys in $\mathrm{PBS}$ at $37^{\circ} \mathrm{C}$.

\begin{tabular}{lcccc}
\hline & \% H decrease & \multicolumn{3}{c}{ \% $_{\text {mech }}$ increase } \\
\hline & & $\mathbf{0 V}$ & $\mathbf{1 V}$ & $\mathbf{2 V}$ \\
\hline Ti30Nb2Sn & 0.81 & 5.6 & 8.1 & 35.4 \\
Ti30Nb4Sn & 5.2 & 33.1 & 33.2 & 47.4 \\
\hline
\end{tabular}

\subsection{Influence of applied potential on the tribocorrosion behavior of Ti30NbxSn alloys}

Titanium alloys show a passive behavior under all the selected potential range. There is a lineal trend of $\mathrm{V}_{\text {wac }}$ with applied potential for all the studied alloys due to the active dissolution of the metal in the wear track. Ti30 Nb and Ti30Nb2 Sn show the same $\mathrm{V}_{\text {wac }}$ increase with the applied potential, while the relationship between $\mathrm{V}_{\text {wac }}$ and the applied potential for the Ti30Nb4Sn increases by a factor of 1.5. This is in good agreement with the influence of $\mathrm{Sn}$ above $2 \%$ in the active and passive dissolution of the alloy.

There is no influence of the applied potential on the $\mathrm{V}_{\text {mech }}$ of the titanium alloys. This is not surprising since the passive film thickness does not really change with the selected potentials [40]. According to the passivation kinetics of the studied alloys, Figure 3, they completely repassivates during each stroke (every 1 second). Therefore, the amount of oxidized and removed material is the same independently on the potential. Considering $10 \mathrm{~nm}$ average thickness of the passive layer, after 3600 seconds, $36 \mu \mathrm{m}$ of oxide film is removed at the end of the test, which taking into account the area of the wear track makes $0.68 \mathrm{~mm}^{3}$ of oxidized material loss. Comparing the amount of total material loss, Table 8, with the oxidized material removed, it is possible to conclude that between $90 \%$ and $70 \%$ of the mechanically detached material is in form of oxide. This occurs at all selected potentials, at which passive kinetics is very similar.

\subsection{Tribocorrosion mechanisms: wear accelerated corrosion}

In case of passive metal, the wear accelerated corrosion volume manifest itself in tribocorrosion tests carried out under imposed passive potential by an increase in current. Existing models are be able to predict the electrochemical response of a tribocorrosion system modeling the anodic current $I_{w a c}$ as a function of mechanical parameters of the material $[41,42]$. Taking into account the contact mechanics of the ball into the sample and the material properties of the sample, the $\mathrm{I}_{\mathrm{wac}}$ can be defined as follows [42]:

$$
I_{w a c}=\frac{0.55 k v_{s} F_{n}^{2 / 3} E^{\prime 1 / 3} Q_{p}}{R^{1 / 3} H}
$$


Where $\mathrm{k}$ is a probability factor (0 to 1 ) taking into account that not all asperity junctions necessarily lead to depassivation, $v_{\mathrm{s}}$ is the sliding velocity in $\mathrm{m} / \mathrm{s}, \mathrm{F}_{\mathrm{N}}$ is the normal force in N, E' is the reduced Young Modulus [43], $\mathrm{Q}_{\mathrm{p}}$ is the charge density in $\mathrm{C} / \mathrm{m}^{2}, \mathrm{R}$ is the radius of the ball in $\mathrm{m}$ and $\mathrm{H}$ is the indentation hardness.

Figure 9 shows the anodic current during sliding $I_{w a c}$ (shown in Table 7) as a function of $\mathrm{Q}_{\mathrm{p}} / \mathrm{H}$. The charge density values are shown in Table 3. It is found a linear relationship for the tests carried out at passive potentials, which indicates the applicability of the Equation 4 to the prediction of $I_{w a c}$ for the studied alloys.

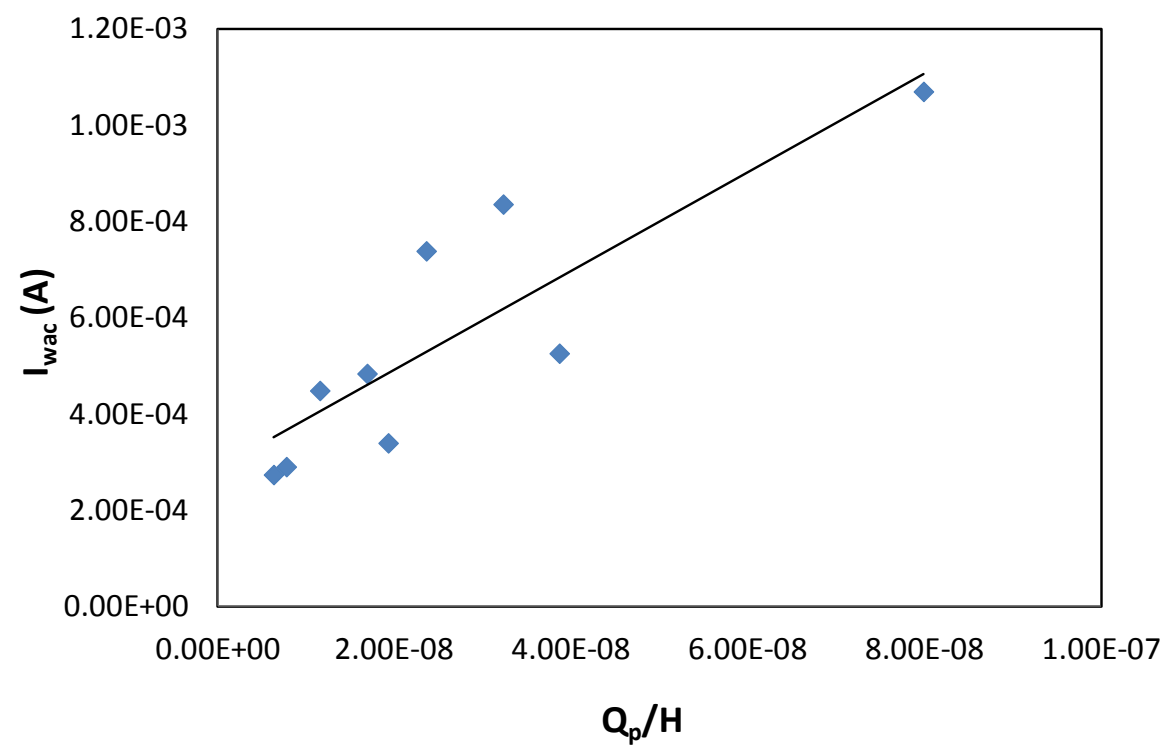

Figure 9. Anodic current as a function of the charge density and the inverse of the hardness for the tribocorrosion tests under passive potentials.

According to this simple but predictive model, design of titanium alloys for biomedical applications may have high hardness simultaneously to low passive charge density. From this point of view Ti30Nb alloyed with Sn may not include more than $2 \%$ of Sn.

The possibility of using sintered TiNbSn alloys for biomedical applications, cardiovascular (stent, artificial valve), orthopedic (bone fixation, artificial joints) dentistry (orthodontic wire, filling) and craniofacial (plate and screw) constitutes a promising alternative to pure $\mathrm{Ti} \mathrm{cp}$ and the classical Ti6Al4V alloy. This is due to their inertness and structural functions; they do not possess biofunctionalities like blood compatibility, bone conductivity and bioactivity. TiNbxSn alloys are a good example of beta-titanium alloys which have the main advantage of decreasing the Young modulus, thus reducing the stress-shielding problem between the bone and the implant. However, further research is needed for its real clinical applications. In-vitro electrochemical and tribo-electrochemical testing (including the behavior under fretting-fatigue-corrosion conditions) in a more complex medium (i.e. in presence of cells) or biological 
compatibility in-vivo is needed. The present study can be considered as the first step which, from a mechanistic point of view, has characterized the tribocorrosion degradation mechanism of TiNbSn alloys in a simple simulated body fluid.

\section{Conclusions}

The following conclusions can be drawn from the study of the tribocorrosion behavior of $\beta$ titanium alloys Ti30NbxSn, where the " $\mathrm{x}$ " is 2 or 4 depending to the weight percentage of $\mathrm{Sn}$ in the alloy.

All alloys spontaneously passivate in PBS solution and they degrade through the same tribocorrosion mechanisms (passive dissolution and plastic deformation). The passive dissolution rate increases with the Sn addition in the TiNbxSn alloy.

Corrosion increases during wear due to the mechanical destruction of the thin oxide film protecting the titanium alloys surface. The increase in the mechanically activated corrosion is 1.5 higher in Ti30Nb4Sn when compared to the Ti30Nb2Sn and $\mathrm{Ti} 30 \mathrm{Nb}$.

Sn content above $2 \%$ in the TiNbxSn alloy decreases the corrosion resistance and the hardness of the alloys, which implies an abrupt increase of mechanical wear and thus wear of the titanium alloys.

Existing models described wear accelerated corrosion under tribocorrosion conditions as a function of electrochemical and mechanical parameters of the alloys. They accurately predict the electrochemical and triboelectrochemical response of the Ti30NbxSn studied alloys.

According to the obtained results Ti30Nb2Sn can be considered the most suitable alloy under tribocorrosion and corrosion conditions.

\section{Acknowledgements}

The authors would like to thank the Ministerio de Ciencia e Innovación of the Spanish government for the financial support under the project MAT2011-22481.

\section{References}

[1] É. Martin, M. Azzi, G.A. Salishchev, J. Szpunar, Influence of microstructure and texture on the corrosion and tribocorrosion behavior of Ti-6Al-4V, Tribol. Int. 43 (2010) 918-924.

[2] M. Nosonovsky, B. Bhushan, Green tribology: principles, research areas and challenges, Philos. Trans. R. Soc. A Math. Physical Eng. Sci. 368 (2010) 46774694. 
[3] N.S. More, N. Diomidis, S.N. Paul, M. Roy, S. Mischler, Tribocorrosion behavior of $\beta$ titanium alloys in physiological solutions containing synovial components, Mater. Sci. Eng. C. 31 (2011) 400-408.

[4] M. Atapour, A.L. Pilchak, G.S. Frankel, J.C. Williams, Corrosion behavior of $\beta$ titanium alloys for biomedical applications, Mater. Sci. Eng. C. 31 (2011) 885-891.

[5] A. Curtis, C. Wilkinson, Topographical control of cells, Biomaterials 18 (1997) 1573-1583.

[6] A. Wennerberg, T. Albrektsson, Effects of titanium surface topography on bone integration: a systematic review, Clin Oral Implant Res 20 (2009) 172-184.

[7] E.S.N. Lopes, R. Cremasco, Alessandra Contieri, R. Caram, Effects of Aging Heat Treatment on the Microstructure of Ti-Nb and Ti-Nb-Sn Alloys Employed as Biomaterials, Adv. Mater. Res. 324 (2011) 61-64.

[8] E.S.N. Lopes, A. Cremasco, C.R.M. Afonso, R. Caram, Effects of double aging heat treatment on the microstructure, Vickers hardness and elastic modulus of Ti-Nb alloys, Mater. Charact. 62 (2011) 673-680.

[9] M.M. Dewidar, J.K. Lim, Properties of solid core and porous surface Ti-6Al-4V implants manufactured by powder metallurgy, J. Alloys Compd. 454 (2008) 442446.

[10] J. Jakubowicz, G. Adamek, Preparation and properties of mechanically alloyed and electrochemically etched porous Ti-6Al-4V, Electrochem. Commun. 11 (2009) 1772-1775.

[11] Y.J. Jo, C.M. Lee, H.S. Jang, N.S. Lee, J.-H. Suk, W.H. Lee, Mechanical properties of fully porous and porous-surfaced Ti-6Al-4V implants fabricated by electro-discharge-sintering, J. Mater. Process. Technol. 194 (2007) 121-125.

[12] V. Barranco, M.L. Escudero, M.C. García-Alonso, Influence of the microstructure and topography on the barrier properties of oxide scales generated on blasted Ti6Al4V surfaces, Acta Biomater. 7 (2011) 2716-2725.

[13] E.B. Taddei, V.A.R. Henriques, C.R.M. Silva, C.A.A. Cairo, Production of new titanium alloy for orthopedic implants, Mater. Sci. Eng. C. 24 (2004) 683-687.

[14] F. Devesa, S. Rial, V. Amigó, Processing and Characterization of $\beta$-Ti Alloys by Means of Powder Metallurgy Processing and Blender Elemental, Mater. Sci. Forum. 727-728 (2012) 61-66.

[15] A. Dalmau, V. Guiñón Pina, F. Devesa, V. Amigó, A. Igual Muñoz, Electrochemical behaviour of near-beta titanium biomedical alloys in phosphate buffer saline solution, Mat. Sci. and Tech. C. (2014) DOI: 10.1016/j.msec.2014.11.036.

[16] M. Niinomi, Fatigue performance and cyto-toxicity of low rigidity titanium alloy, Ti29Nb13Ta4.6Zr, Biomaterials 24 (2003) 2673-2683. 
[17] K. Miura, N. Yamada, S. Hanada, T.K. Jung, E. Itoi, The bone tissue compatibility of a new TiNbSn alloy with a low Young's modulus, Acta Biomaterialia 7 (2011) 2320-2326.

[18] X. Wang, Y. Chen, L. Xu, Z. Liu, K.D. Woo, Effects of Sn content on the microstructure, mechanical properties and biocompatibility of Ti-NbSn/hydroxyapatite biocomposites synthesized by powder metallurgy, J. Materials and Design 49 (2013) 511-519.

[19] A. Cremasco, A.D. Messias, A.R. Esposito, E.A.R. Duek, R. Caram, Effects of alloying elements on the cytotoxic response of titanium alloys, Mater. Sci. Eng. C. 31 (2011) 833-839.

[20] S. Yua, Z. Yua, G. Wangb, J. Hana, X. Maa, M.S. Dargusch, Biocompatibility and osteoconduction of active porous calcium-phosphate films on a novel Ti-3Zr-2Sn3Mo-25Nb biomedical alloy, Colloids Surf. B 85 (2011) 103-115.

[21] F. Galliano, E. Galvanetto, S. Mischler, D. Landolt, Tribocorrosion behavior of plasma nitrided Ti-6Al-4V alloy in neutral $\mathrm{NaCl}$ solution, Surf. Coatings Technol. 145 (2001) 121-131.

[22] E. Arslan, Y. Totik, I. Efeoglu, The investigation of the tribocorrosion properties of DLC coatings deposited on Ti6Al4V alloys by CFUBMS, Prog. Org. Coatings. 74 (2012) 768-771.

[23] P. Jemmely, S. Mischler, D. Landolt, Tribocorrosion behaviour of $\mathrm{Fe}-17 \mathrm{Cr}$ stainless steel in acid and alkaline solutions, Tribol. Int. 32 (1999) 295-303.

[24] D. Landolt, S. Mischler, M. Stemp, S. Barril, Third body effects and material fluxes in tribocorrosion systems involving a sliding contact, Wear 256 (2004) 517524.

[25] S. Mischler, Triboelectrochemical techniques and interpretation methods in tribocorrosion: A comparative evaluation, Tribol. Inter. 41 (2008) 573-583

[26] N. Papageorgiou, S. Mischler, Electrochemical Simulation of the Current and Potential Response in Sliding Tribocorrosion, Tribol. Lett. 48 (2012) 271-283.

[27] M.T. Mathew, P.S. Pai, R. Pourzal, A. Fischer, M.A. Wimmer, Significance of Tribocorrosion in Biomedical Applications: Overview and Current Status, Advances in Tribology vol. 2009 (2009) DOI: doi:10.1155/2009/250986.

[28] A.C. Alves, F. Oliveira, F. Wenger, P. Ponthiaux, J.P. Celis, L.A. Rocha, Tribocorrosion behaviour of anodic treated titanium surfaces intended for dental implants, J. Phys. D: Appl. Phys. 46 (2013) 404001 (9pp).

[29] C. Yuyong, W. Xiaopenga, X. Lijuana, L. Zhiguanga, K. D. Woob, Tribological behavior study on TiNbSn/hydroxyapatite composites in simulated body fluid solution, Journal of the Mechanical Behavior of Biomedical Materials 10 (2012) 97107. 
[30] M.K. Dimah, F. Devesa Albeza, V. Amigo Borras, A. Igual Muñoz, Study of the biotribocorrosion behaviour of titanium biomedical alloys in simulated body fluids by electrochemical techniques, Wear 294-295 (2012) 409-418

[31] M.P. Licausi, A. Igual Muñoz, V. Amigo Borras, Tribocorrosion mechanisms of Ti6Al4V biomedical alloys in artificial saliva with different $p H s$, J. Phys. D: Appl. Phys. 46 (2013) 404003 (10pp).

[32] S. Mischler, A. Spiegel, D. Landolt, The role of passive oxide films on the degradation of steel in tribocorrosion systems, Wear 225-229 (1999) 1078-1087.

[33] R. Priya, C. Mallika, U.K. Mudali, Wear and tribocorrosion behaviour of 304L SS, Zr-702, Zircaloy-4 and Ti-grade2, Wear 310 (2014) 90-100.

[34] M. Azzi, M. Paquette, J.A. Szpunar, J.E. Klemberg-Sapieha, L. Martinu, Tribocorrosion behaviour of DLC-coated 316L stainless steel, Wear 267 (2009) 860-866.

[35] J. Perret, E. Boehm-Courjault, M. Cantoni, S. Mischler, A. Beaudouin, W. Chitty, J.P. Vernot, EBSD, SEM and FIB characterisation of subsurface deformation during tribocorrosion of stainless steel in sulphuric acid, Wear 269 (2010) 383-393.

[36] M. Stemp, S. Mischler, D. Landolt, The effect of mechanical and electrochemical parameters on the tribocorrosion rate of stainless steel in sulphuric acid, Wear 255 (2003) 466-475.

[37] Y. Sun, E. Haruman, Effect of electrochemical potential on tribocorrosion behavior of low temperature plasma carburized 316L stainless steel in $1 \mathrm{M} \mathrm{H2SO4}$ solution, Surf. Coatings Technol. 205 (2011) 4280-4290.

[38] A.C. Vieira, L.A. Rocha, N. Papageorgiou, S. Mischler, Mechanical and electrochemical deterioration mechanisms in the tribocorrosion of Al alloys in $\mathrm{NaCl}$ and in NaNO3 solutions, Corros. Sci. 54 (2012) 26-35.

[39] C.O. A. Olsson, D. Hamm, D. Landolt, Evaluation of Passive Film Growth Models with the Electrochemical Quartz Crystal Microbalance on PVD Deposited Cr, J. Electrochem. Soc. 147 (2000) 4093-4102

[40] I. Milosev, G. Zerjav, J.M. Calderon Moreno, M. Popa, Electrochemical properties, chemical composition and thickness of passive film formed on novel Ti20Nb-10Zr-5Ta alloy, Electrochim. Acta 99 (2013) 176- 189.

[41] D. Landolt, S. Mischler, M. Stemp, Electrochemical methods in tribocorrosion: a critical appraisal, Electrochim. Acta 46 (2001) 3913-3929.

[42] S. Mischler, Sliding Tribo-Corrosion of Passive Metals: Mechanisms and Modeling, in: B. Peter, C. Jean-Pierre, D. Dirk, F. Friedrich (Eds.), Tribo-Corrosion Res. Testing, Appl., ASTM international (2013) 1-18.

[43] G. Stachowiak, A.W. Batchelor, Engineering Tribology, Elsevier Science (2011). 